\title{
Evaluation of toothbrush disinfection via different methods
}

\section{Adil BASMAN(a) \\ Ilkay PEKER ${ }^{(b)}$ \\ Gulcin AKCA ${ }^{(c)}$ \\ Meryem Toraman ALKURT ${ }^{(b)}$ \\ Cigdem SARIKIR ${ }^{(b)}$ \\ Irem CELIK(c)}

(a)Gazi University, Faculty of Dentistry, Department of Periodontology, Ankara, Turkey.

(b) Gazi University, Faculty of Dentistry, Department of Dentomaxillofacial

Radiology, Ankara, Turkey.

(c)Gazi University, Faculty of Dentistry, Department of Microbiology, Ankara, Turkey.

Declaration of Interests: The authors certify that they have no commercial or associative interest that represents a conflict of interest in connection with the manuscript.

Corresponding Author:

Ilkay Peker

E-mail: drilkaypeker@gmail.com

DOI: 10.1590/1807-3107BOR-2016.vol30.0006

Submitted: Feb 11, 2015

Accepted for publication: Jul 07, 2015

Last revision: Aug 28, 2015
Abstract: The aim of this study was to compare the efficacy of using a dishwasher or different chemical agents, including $0.12 \%$ chlorhexidine gluconate, $2 \%$ sodium hypochlorite $(\mathrm{NaOCl})$, a mouthrinse containing essential oils and alcohol, and 50\% white vinegar, for toothbrush disinfection. Sixty volunteers were divided into five experimental groups and one control group $(n=10)$. Participants brushed their teeth using toothbrushes with standard bristles, and they disinfected the toothbrushes according to instructed methods. Bacterial contamination of the toothbrushes was compared between the experimental groups and the control group. Data were analyzed by Kruskal-Wallis and Duncan's multiple range tests, with 95\% confidence intervals for multiple comparisons. Bacterial contamination of toothbrushes from individuals in the experimental groups differed from those in the control group $(p<0.05)$. The most effective method for elimination of all tested bacterial species was 50\% white vinegar, followed in order by $2 \% \mathrm{NaOCl}$, mouthrinse containing essential oils and alcohol, $0.12 \%$ chlorhexidine gluconate, dishwasher use, and tap water (control). The results of this study show that the most effective method for disinfecting toothbrushes was submersion in $50 \%$ white vinegar, which is cost-effective, easy to access, and appropriate for household use.

Keywords: Disinfection; Hygiene; Toothbrushing.

\section{Introduction}

Many bacteria are found in toothbrushes after brushing. These microorganisms can remain viable for a day to a week after brushing. ${ }^{1}$ Contaminated toothbrushes may play an important role in many oral and systemic diseases, including septicemia and gastrointestinal, cardiovascular, respiratory, and renal problems. ${ }^{2}$ Toothbrushes can become contaminated from the oral cavity, environment, hands, aerosol contamination, and storage containers. ${ }^{3}$ Toothbrushes are frequently stored in the bathroom or close to the toilet and sink. As a result, they may be exposed to enteric bacteria dispersed by aerosols. ${ }^{4}$ Even small droplets from the toilet lead to the release of millions of bacteria into the atmosphere. ${ }^{5}$

Patients with oral diseases experienced a decrease of symptoms when they changed their toothbrushes during the disease. ${ }^{6}$ The American Dental Association (ADA) recommends changing toothbrushes once every 3 months. ${ }^{7}$ Previous studies suggested that patients with systemic diseases or undergoing organ transplantation or chemotherapy should 
change their toothbrushes more frequently. $6,7,8$ The ADA suggests soaking used toothbrushes in antimicrobial mouthrinses for patients in high-risk groups. ${ }^{7}$ Information about the use and handling of toothbrushes can be found in guidelines of the Centers for Disease Control (CDC). ${ }^{9}$ These guidelines suggest that people who are immunosuppressed may need to seek alternative means of oral hygiene, because toothbrushes can remain contaminated with potentially pathogenic organisms even after thorough rinsing with tap water. The CDC has proposed an especially high risk of cross-contamination in group and school settings, perhaps because of a lack of proper handling or storage of toothbrushes.

Different methods for toothbrush disinfection have been investigated. However, this issue has received little attention from many researchers because most clinicians only consider toothbrushes from the perspective of their role in caries and plaque prevention. ${ }^{5}$ Furthermore, although some laboratory studies related to toothbrush disinfection have been carried out, ${ }^{10,11,12,13,14}$ few such studies have been performed with volunteers. ${ }^{15,16,17}$ Therefore, the aim of this study was to compare the efficacy of using a dishwasher or different chemical agents, including $0.12 \%$ chlorhexidine gluconate, $2 \%$ sodium hypochlorite $(\mathrm{NaOCl})$, a mouthrinse containing essential oils and alcohol and 50\% white vinegar, for bacterial disinfection of toothbrushes.

\section{Methodology}

This study was approved by the Institutional Ethics Committee of Gazi University Faculty of Medicine (20.01.2014-No:45). All participants provided written informed consent before enrollment. The study included 60 volunteers who had at least 24 caries-free teeth, a healthy gingiva, and no systemic or oral mucosal diseases. Participants were excluded if they were pregnant or lactating, smokers, or had used any antibiotic within the last 3 months. Participants were divided into five experimental groups and one control group $(\mathrm{n}=10$, Table 1$)$.

Each participant was provided a toothbrush (Colgate Micro Sensitive, Colgate Palmolive Company, Ankara, Turkey) with standard bristles, a vented custom container, and a container of toothpaste (Colgate Total, Colgate Palmolive Company) (Table 1). ${ }^{2,15}$ Disposable sterile pouches were provided for the transport of toothbrushes to the laboratory. Participants in the dishwasher group (Table 1) were provided dishwasher detergent (Finish Powerball, Reckitt Benckiser, Istanbul, Turkey) to ensure standardization.

Participants were instructed to brush their teeth twice a day (morning and night) for 7 days and to disinfect their toothbrushes with suggested methods. After brushing, participants in the chemical agent groups were instructed to rinse their toothbrushes under tap water, place their toothbrushes in $50 \mathrm{~mL}$ of chemical agent in a sterile container, and again rinse their toothbrushes under tap water (Table 1). Participants in the dishwasher group were instructed to wash their toothbrushes in the dishwasher with the given detergent at $70^{\circ} \mathrm{C}$ under the normal cleaning cycle once a day. Participants in the control group were instructed to wash their toothbrushes under tap water after brushing their teeth.

All participants were expected to store their toothbrushes in the provided vented custom container, which allowed air circulation while

Table 1. The methods of disinfection examined in this study.

\begin{tabular}{lr} 
Groups & Methods \\
\hline Group 1 & Toothbrushes were disinfected with $50 \%$ white vinegar (Attun Ltd., Antakya, Turkey) \\
Group 2 & Toothbrushes were disinfected with $0.12 \%$ chlorhexidine gluconate (Klorheks, Drogsan Pharmaceuticals, Ankara, Turkey) \\
Group 3 & Toothbrushes were disinfected with $2 \% \mathrm{NaOCl}$ (Tipkimsan Ltd., Istanbul, Turkey) \\
Group 4 & Toothbrushes were disinfected with dishwasher (Arcelik Ltd., Istanbul, Turkey) \\
Group 5 & Toothbrushes were disinfected with essential oils and alcohol (Listerine, Johnson \& Johnson Healthcare Products, Istanbul, Turkey) \\
Group 6 & Toothbrushes were washed with tap water \\
(control) &
\end{tabular}


avoiding external contamination. Toothbrushes were to be dried at room temperature for 4 hours, simulating the interval between toothbrushing sessions. ${ }^{2,15}$ After 7 days, participants returned their toothbrushes to the researchers $(\mathrm{AB}, \mathrm{CS})$ in the vented custom containers, which were placed in disposable sterile plastic pouches. The toothbrushes were sent to the laboratory immediately.

Bacterial contamination of toothbrushes after 7 days of use was compared between toothbrushes from individuals in experimental groups and in the control group. To measure contamination, toothbrushes were immersed and incubated in tubes containing $5 \mathrm{~mL}$ of phosphate-buffered saline solution (PBS, $\mathrm{pH}$ 7.2) at $37^{\circ} \mathrm{C}$ under anaerobic conditions for 48 hours. After vortexing rigorously for 1 minute, all tubes were diluted to $10^{-2}$ and $10^{-3}$. Next, $25-\mu 1$ aliquots of the specimens were seeded onto BHI agar (Merck, Darmstadt, Germany) for isolation of Staphylococcus aureus and Escherichia coli, TYC agar (Merck) for Streptococcus mutans, and MRS agar (Merck) for Lactobacillus rhamnosus. Specimens were incubated as mentioned above, and the grown colonies were counted. The number of colonies was calculated according to the dilution ratio and defined as the number of colony forming units (cfu) per milliliter.

Data were statistically analyzed by using the SPSS software package for Windows (version 15.0; SPSS Inc., Chicago, USA). Means, standard deviations, and medians for data of each microorganism after disinfection with different methods were calculated with descriptive statistics and analyzed by the Kruskal-Wallis test. Duncan's multiple range test was performed to compare the effectiveness of the methods. A p-value of 0.05 was considered as the level of significance.

\section{Results}

Statistically significant differences were found between the experimental groups and the control group for the numbers of $S$. mutans and E. coli bacteria (Table 2). There were no statistically significant differences between the experimental groups and the control group in terms of L. rhamnosus or S. aureus bacteria (Table 2). A statistically significant difference was found between the experimental groups and the control group regardless of the type of bacteria (Table 3). The most effective method was 50\% white vinegar, followed by $2 \% \mathrm{NaOCl}$, Listerine, $0.12 \%$ chlorhexidine gluconate, dishwashing, and tap water (control), respectively, when considering the numbers of all types of bacteria (Table 4).

\section{Discussion}

In the present study, different chemical antimicrobial agents and dishwashers were used for toothbrush disinfection due to their accessibility, cost-effectiveness, and potential antibacterial effects. The study was performed by volunteers to simulate the natural conditions of daily life.

$\mathrm{NaOCl}$ is widely used as a root canal irrigant in endodontics because of its broad antimicrobial activity. The cytotoxic properties of $2-2.5 \% \mathrm{NaOCl}$ do not appear during short-term exposure, and no genotoxic effect has been found for host tissues. ${ }^{18}$ Mobin et al. ${ }^{10}$ investigated fungal contamination in toothbrushes

Table 2. The results of Kruskal Wallis test according to each bacteria.

\begin{tabular}{|c|c|c|c|c|c|c|c|c|c|c|c|}
\hline \multirow{3}{*}{ Groups } & \multicolumn{11}{|c|}{ Tested bacteria } \\
\hline & \multicolumn{3}{|c|}{ L.rhamnosus } & \multicolumn{3}{|c|}{ S.mutans } & \multicolumn{3}{|c|}{ S.aureus } & \multicolumn{2}{|l|}{ E.coli } \\
\hline & $\begin{array}{c}\text { Mean } \pm \text { Standard } \\
\text { deviation }\end{array}$ & $\begin{array}{l}\text { Kruskal } \\
\text { wallis }\end{array}$ & p-value & $\begin{array}{c}\text { Mean } \pm \text { Standard } \\
\text { deviation }\end{array}$ & $\begin{array}{l}\text { Kruskal } \\
\text { wallis }\end{array}$ & p-value & $\begin{array}{c}\text { Mean } \pm \text { Standard } \\
\text { deviation }\end{array}$ & $\begin{array}{l}\text { Kruskal } \\
\text { wallis }\end{array}$ & p-value & $\begin{array}{c}\text { Mean } \pm \text { Standard } \\
\text { deviation }\end{array}$ & $\begin{array}{l}\text { Kruskal } \\
\text { wallis }\end{array}$ \\
\hline Group 1 & $0.00 \pm 0.00$ & 10.687 & 0.058 & $0.00 \pm 0.00$ & 19.060 & $0.002^{*}$ & $50.00 \pm 158.11$ & 5.842 & 0.322 & $0.00 \pm 0.00$ & $16.1860 .006^{*}$ \\
\hline Group 2 & $250.00 \pm 634.65$ & & & $0.00 \pm 0.00$ & & & $400.00 \pm 658.28$ & & & $200.00 \pm 632.46$ & \\
\hline Group 3 & $556.00 \pm 1.758 .23$ & & & $0.00 \pm 0.00$ & & & $50.00 \pm 158.11$ & & & $0.00 \pm 0.00$ & \\
\hline Group 4 & $1.476 .00 \pm 1.881 .13$ & & & $600.00 \pm 1.264 .91$ & & & $710.00 \pm 1.781 .67$ & & & $127.000 .00 \pm 389.809 .36$ & \\
\hline Group 5 & $3.200 .00 \pm 5.593 .65$ & & & $0.00 \pm 0.00$ & & & $0.00 \pm 0.00$ & & & $0.00 \pm 0.00$ & \\
\hline Group 6 & $783.60 \pm 1.763 .74$ & & & $634.00 \pm 953.50$ & & & $1.080 .00 \pm 2.015 .94$ & & & $230.068 .00 \pm 711.937 .29$ & \\
\hline
\end{tabular}

*Difference is statistically significant at the $95 \%$ confidence interval. 
Table 3. The results of Kruskal Wallis test performed regardless of the type of the bacteria.

\begin{tabular}{lccc}
\hline Groups & Mean \pm Standard deviation & Kruskal wallis & $p$-value \\
\hline Group 1 & $12.50 \pm 39.53$ & 25.301 & $0.000^{*}$ \\
Group 2 & $212.50 \pm 243.31$ & & \\
Group 3 & $151.50 \pm 436.93$ & & \\
Group 4 & $32.446 .50 \pm 97.392 .86$ & & \\
Group 5 & $800.00 \pm 1.398 .41$ & & \\
Group 6 & $58.141 .40 \pm 178.248 .83$ & & \\
\hline
\end{tabular}

*Difference is statistically significant at the $95 \%$ confidence interval.

Table 4. Efficacy of all tested methods according to Duncan's multiple range test.

\begin{tabular}{lcc}
\hline Order of & & Subset for al pha $=0.05$ \\
\cline { 3 - 3 } Duncan's & Methods & 1 \\
\hline 1 & Group 1 & 12.5000 \\
2 & Group 3 & 151.5000 \\
3 & Group 5 & 212.5000 \\
4 & Group 2 & 800.0000 \\
5 & Group 4 & 32.446 .5000 \\
6 & Group 6 & 58.141 .4000 \\
& Sig. & 0.177 \\
\hline
\end{tabular}

and suggested that submersion in $2 \% \mathrm{NaOCl}$ for 3-5 minutes is an effective and low-cost method to disinfect a toothbrush. Silva et al..$^{19}$ investigated the effectiveness of different solutions for disinfecting acrylic resin specimens contaminated with Candida albicans, S. mutans, S. aureus, E. coli, and Bacillus subtilis. They found $1 \% \mathrm{NaOCl}$ to be the best antimicrobial agent against the tested microorganisms. ${ }^{20}$ This result was supported by Salvia et al. ${ }^{20}$ Similarly, in this study, $2 \% \mathrm{NaOCl}$ significantly reduced the counts of all tested microorganisms and virtually eradicated S. mutans and $E$. coli. This chemical agent was the second-most effective method against all tested bacteria. This result is in accordance with previous studies.

Although white vinegar is not commonly used for disinfection in dentistry, this solution is preferred as a promising alternative disinfectant in several areas. ${ }^{21}$ There are a few studies on the use of white vinegar in dentistry. White vinegar has frequently been used at $50 \%$ and $100 \%$ concentrations to disinfect toothbrushes and acrylic resins. ${ }^{19,20}$ Silva et al. ${ }^{19}$ reported that $100 \%$ white vinegar has good antimicrobial activity against $C$. albicans and $S$. aureus for acrylic resins. This result was supported by Salvia et al., ${ }^{20}$ who remarked that this agent is as effective as $1 \% \mathrm{NaOCl}$ and $2 \%$ chlorhexidine gluconate against $C$. albicans, E. coli, and S. mutans. In contrast, Komiyama et al. ${ }^{11}$ found $50 \%$ white vinegar to be effective in toothbrush disinfection for S. aureus, S. mutans, and Streptococcus pyogenes, but not $C$. albicans. In the present study, use of $50 \%$ white vinegar for 10 minutes was the most effective method against all bacteria.

The bacteriostatic and bactericidic effects of mouthwashes containing essential oils are well-known. Their antiplanktonic effect is better than their antibiofilm activity, and these mouthwashes could be considered as a good choice for the prevention of systemic bacterial dissemination. ${ }^{22}$ Mouthwashes containing essential oils and alcohol, such as Listerine, have the best antibiofilm activity and could be used to prevent plaque formation after periodontal treatment. ${ }^{23,24}$ Previous studies ${ }^{25,26}$ reported that Listerine could reduce the number of oral bacteria significantly. ${ }^{26}$ Belanger-Giguere et al. ${ }^{25}$ used Listerine for 20 minutes to disinfect toothbrushes and reported that its effectiveness was lower than that of mouthwashes with chlorhexidine. In contrast, the present study found Listerine to be more effective than chlorhexidine. Furthermore, Listerine was the third-most effective chemical agent against all tested bacteria, after $50 \%$ white vinegar and $2 \% \mathrm{NaOCl}$.

Belanger-Giguere et al. ${ }^{25}$ suggested dishwasher use for toothbrush disinfection. In their study, using the dishwasher under the normal cycle at a high temperature was a significantly effective method against $S$. mutans. In this study, the dishwasher was chosen for testing due to its easy accessibility and cost effectiveness. To ensure standard conditions, the same type of detergent was given to all participants, who were instructed on how to use the dishwasher. In contrast with the previous study, this paper found the dishwasher to be the least effective method. However, the study of Belanger-Giguere et al. ${ }^{25}$ was an in vitro study and used a single type of dishwasher, whereas the present study was performed with volunteers and, probably, different types of dishwashers. The discrepancy of results between the studies may be related to these differences. 
This study was performed by volunteers, and the study design was intended to simulate the natural conditions of daily life. However, in vitro circumstances generally are more standardized than natural life and are controllable by researchers. The use of volunteers may be considered a limitation of the study, especially because different dishwasher brands were used by participants in the dishwasher group. To our knowledge, the present study is the second report of using a dishwasher for toothbrush disinfection. Further studies should test the efficacy of dishwasher use for toothbrush disinfection. Previous papers ${ }^{13,25}$ have studied the efficacy of different toothbrush disinfection methods against $S$. mutans, S. aureus, and E. coli. However, to our knowledge, the influence of the toothbrush disinfection method for L. rhamnosus has not been studied, except for our previous in vitro study. ${ }^{21}$ This is the first study in the literature performed by volunteer subjects for L. rhamnosus.

\section{References}

1. Efstratiou M, Papaioannou W, Nakou M, Ktenas E, Vrotsos IA, Panis V. Contamination of a toothbrush with antibacterial properties by oral microorganisms. J Dent. 2007;35(4):331-7. doi:10.1016/j.jdent.2006.10.007

2. Nascimento AP, Watanabe E, Ito IY. Toothbrush contamination by Candida spp. and efficacy of mouthrinse spray for their disinfection. Mycopathologia. 2010;169(2):133-8. doi:10.1007/s11046-009-9239-z

3. Frazelle MR, Munro CL. Toothbrush contamination: a review of the literature. Nurs Res Pract.. 2012;2012:420630. doi:10.1155/2012/420630

4. Taji SS, Rogers AH. The microbial contamination of toothbrushes. A pilot study. Aust Dent J. 1998;43(2):128-30. doi:10.1111/j.1834-7819.1998.tb06101.x

5. Ankola AV, Hebbal M, Eshwar S. How clean is the toothbrush that cleans your tooth? Int J Dent Hyg. 2009;7(4):237-40. doi:10.1111/j.1601-5037.2009.00384.x

6. Glass RT, Jensen HG. More on the contaminated toothbrush: the viral story. Quintessence Int. 1988;19(10):713-6.

7. American Dental Association-ADA. ADA Positions, Policies and Statements. Toothbrush care: cleaning, storage, and replacement. 2005 [cited 2011 Apr 21]..Available from: http://www.ada.org/en/ about-the-ada/ada-positions-policies-and-statements/statementon-toothbrush-care-cleaning-storage-and-

8. Bhat SS, Hegde KS, George RM. Microbial contamination of toothbrushes and their contamination. J Indian Soc Pedod Prev Dent. 2003;21(3):108-12.

\section{Conclusion}

All of the methods tested, including antimicrobial chemical agents and dishwasher use, were effective to reduce the bacterial counts of $S$. mutans, S. aureus, E. coli, and L. rhamnosus in toothbrushes. However, the most effective method for all tested bacteria was $50 \%$ white vinegar, which is cost-effective, easy to access, and appropriate for household use. Further studies determining all of the effects of white vinegar, including its biocompatibility or toxicity, may increase clinicians' awareness about its antimicrobial capacity.

\section{Acknowledgements}

The authors wish to thank to Colgate-Palmolive Company (Istanbul, Turkey) for providing the toothbrushes and toothpastes. The authors also thank Dr. Tülin Otbiçer (Specialist in Measurement of Evaluation in Education, Ankara, Turkey) for help in data analysis.

9. Center for Disease Control and Preverntion - CDC, Division of Oral Health. The use and handling of toothbrushes: infection control. [cited 2008 Aug 19]. Available from: http://www.cdc. gov/oralhealth/infectioncontrol/factsheets/toothbrushes.htm

10. Mobin M, Borba CM, Filho CAM, Tapety FI, Noleto IMs, Teles JBM. Analysis of fungal contamination and disinfection of toothbrushes. Acta Odontol Latinoam. 2011;24(1):86-91.

11. Komiyama EY, Back-BritoGN, Balducci I,Koga-Ito CY.Evaluation of alternative methods for the disinfection of toothbrushes. Braz Oral Res. 2010;24(1):28-33. doi:10.1590/S1806-83242010000100005

12. Bertolini PF, Biondi Filho O, Pomilio A, Pinheiro SL, Carvalho MS. Antimicrobial capacity of Aloe vera and mouthrinse containing propolis dentifrice against Streptococcus mutans strains in toothbrushes: an in vitro study. J Appl Oral Sci. 2012;20(1):32-7. doi:10.1590/S1678-77572012000100007

13. Spolidorio DM, Tardivo TA, Dercel JR, Neppelenbroek KH, Duque C, Spolidorio LC et al. Evaluation of two alternative methods for disinfection of toothbrushes and tongue scrapers. Int J Dent Hyg. 2011;9(4):279-83. doi:10.1111/j.1601-5037.2011.00503.x

14. Karibasappa GN, Nagesh L, Sujatha BK. Assessment of microbial contamination of toothbrush head: an in vitro study. Indian J Dent Res. 2011;22(1):2-5. doi:10.4103/0970-9290.79965

15. Nelson-Filho P, Pereira MS, De Rossi A, Silva RA, Mesquita KS, Queiroz AM et al. Children's toothbrush contamination in day-care centers: how to solve this problem? Clin Oral Investig. 2014;18(8):1969-74. doi:10.1007/s00784-013-1169-y 
16. Nascimento CD, Sorgini MB, Pita MS, Fernandes FH, Calefi PL, Watanabe E et al. Effectiveness of three antimicrobial mouthrinses on the disinfection of toothbrushes stored in closed containers: a randomized clinical investigation by DNA Checkerboard and Culture. Gerodontology. 2014;31(3):227-36. doi:10.1111/ger.12035

17. Turner LA, McCombs GB, Hynes WL, Tolle SL. A novel approach to controlling bacterial contamination on toothbrushes: chlorhexidine coating. Int J Dent Hyg, 2009;7(4):241-5. doi:10.1111/j.1601-5037.2008.00352.x

18. Aubut V, Pommel L, Verhille B, Orsière T, Garcia S, About I et al. Biological properties of a neutralized $2.5 \%$ sodium hypochlorite solution. Oral Surg Oral Med Oral Pathol Oral Radiol Endod. 2010;109(2):e120-5. doi:10.1016/j.tripleo.2009.09.022

19. Silva FC, Kimpara ET, Mancini MN, Balducci I, Jorge AO, Koga-Ito CY. Effectiveness of six different disinfectants on removing five microbial species and effects on the topographic characteristics of acrylic resin. J Prosthodont. 2008;17(8):627-33. doi:10.1111/j.1532-849X.2008.00358.x

20. Salvia AC, Matilde FS, Rosa FC, Kimpara ET, Jorge AO, Balducci I et al. Disinfection protocols to prevent cross contamination between dental offices and prosthetic laboratories. J InfectPublic Health. 2013;6(5):377-82. doi:10.1016/j.jiph.2013.04.011
21. Peker I, Akca G, Sarikir C, Toraman Alkurt M, Celik I. Effectiveness of alternative methods for toothbrush disinfection: an in vitro study. Scient World J. 2014;2014:ID726190. doi:10.1155/2014/726190

22. Erriu M, Pili FM, Tuveri E, Pigliacampo D, Scano A, Montaldo C, et al. Oil essentials mouthwashes antibacterial activity against Aggregatibacter actinomycetemcomitans : a comparison between antibiofilm and antiplanktonic effects. Int J Dent. 2013;2013:164267. doi:10.1155/2013/164267

23. Pan PC, Harper S, Ricci-Nittel D, Lux R, Shi W. In-vitro evidence for efficacy of antimicrobial mouthrinses. J Dent. 2010;38 Suppl 1:S16-20. doi:10.1016/S0300-5712(10)70006-3

24. Marchetti E, Mummolo S, Di Mattia J, Casalena F, Di Martino S, Mattei A, Marzo G. Efficacy of essential oil mouthwash with and without alcohol: a 3-day plaque accumulation model. Trials. 2011;12:262. doi:10.1186/1745-6215-12-262

25. Belanger-Giguere K, Giguere S, Belanger M. Disinfection of toothbrushes contaminated with Streptococcus mutans. Am J Dent. 2011;24(3):155-8.

26. Mehta A, Sequeira PS, Bhat G. Bacterial contamination and decontamination of toothbrushes after use. N Y State Dent J. 2007;73(3):20-2. 